\title{
Modified CIM test as a useful tool to detect carbapenemase activity among extensively drug-resistant Klebsiella pneumoniae, Escherichia coli and Acinetobacter baumannii
}

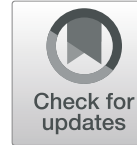

Abed Zahedi Bialvaei ${ }^{1}$ (D) Alireza Dolatyar Dehkharghani ${ }^{2}$, Farhad Asgari ${ }^{2}$, Firouzeh Shamloo ${ }^{2}$, Parisa Eslami ${ }^{3}$ and Mohammad Rahbar ${ }^{*}$

\begin{abstract}
Purpose: Timely detection of carbapenemases is essential for developing strategies to control the spread of infections by carbapenem-resistant isolates. The purpose of this study was to determine the epidemiology of carbapenemase genes among carbapenem-resistant isolates of Acinetobacter baumannii, Klebsiella pneumoniae, and Escherichia coli. In addition, the efficacy of the modified Hodge test (MHT), Carba NP test, and modified carbapenem inactivation method ( $\mathrm{mClM}$ ) were compared.
\end{abstract}

Methods: A total of 122 carbapenem-resistant clinical isolates including 77 K. pneumoniae, 39 A. baumannii, and six E. coli were collected from hospitalized patients. Three phenotypic methods, including the MHT, Carba NP test, and $\mathrm{mCIM}$ were used for investigation of carbapenemase production. In addition, polymerase chain reaction (PCR) was performed to detect carbapenemase-encoding genes.

Result: The sensitivity and specificity of the MHT were $75.0 \%$ and $100 \%$, respectively. In addition, Carba NP displayed $80.8 \%$ sensitivity and $100 \%$ specificity, whereas the sensitivity and specificity were $90.4 \%$ and $100 \%$ for the mCIM test, respectively. Among carbapenem-resistant isolates, 70, 84, and 87 isolates exhibited positive results according to the MHT, Carba NP test, and $\mathrm{mCIM}$, respectively. PCR indicated the presence of one or more carbapenemase genes in 119 of carbapenem-resistant isolates, with bla $a_{\mathrm{KPC}}$ and blavIM being the most commonly encountered. Co-production of 'KPC and OXA-48', 'KPC and VIM', and 'KPC and IMP' was detected in three, nine, and seven isolates, respectively.

Conclusion: Our results confirm that the mCIM test is a useful tool for the reliable detection of carbapenemase activity in enterobacterial isolates, especially in clinical microbiological laboratories with limited resources.

Keywords: Acinetobacter baumannii, Carba NP, Carbapenemase, mCIM, Carbapenem resistance

\footnotetext{
* Correspondence: rahbar.reflab@gmail.com

2Department of Microbiology, Iranian Reference Health Laboratory Research

Center, Ministry of Health and Medical Education, Tehran, Iran

Full list of author information is available at the end of the article
}

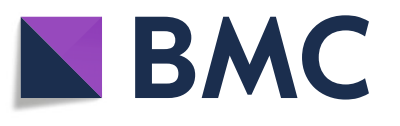

๑ The Author(s). 2021 Open Access This article is licensed under a Creative Commons Attribution 4.0 International License, which permits use, sharing, adaptation, distribution and reproduction in any medium or format, as long as you give appropriate credit to the original author(s) and the source, provide a link to the Creative Commons licence, and indicate if changes were made. The images or other third party material in this article are included in the article's Creative Commons licence, unless indicated otherwise in a credit line to the material. If material is not included in the article's Creative Commons licence and your intended use is not permitted by statutory regulation or exceeds the permitted use, you will need to obtain permission directly from the copyright holder. To view a copy of this licence, visit http://creativecommons.org/licenses/by/4.0/. 


\section{Introduction}

The worldwide emergence and spread of carbapenemase producers represent a significant threat to public health (Bialvaei et al. 2017). Particularly, this may pose a major problem as carbapenems are becoming more frequently needed to treat infections caused by Gram-negative bacilli (GNB) that produce extended-spectrum betalactamases (ESBL) (Vardakas et al. 2012). Carbapenemase enzymes are clustered in different classes that define their hydrolytic profiles; Verona integron-encoded metallo- $\beta$ lactamase (VIM), New Delhi MBL (NDM), and imipenemase (IMP) belong to the Ambler class B metallo-ß-lactamases (MBLs), Klebsiella pneumoniae carbapenemase (KPC) and GES belong to class A, and OXA-48 and OXA-48-like belong to class D (Zahedi Bialvaei et al. 2015). These profiles are associated with resistance to carbapenems and most $ß$-lactam antibiotics. In addition, mobile genetic elements (plasmids, transposons, etc.) that harbor carbapenemase genes have been documented to spread among GNB, making it important to rapidly and efficiently detect all carbapenemase producers to prevent their further spread (Gniadek et al. 2016).

The epidemiology of carbapenemase-producing bacteria varies by country. The prevalence of KPC-producing GNB is unevenly distributed among the USA, and there are less frequent reports of other carbapenemases, including IMP, VIM, NDM, and OXA-48-like enzymes (Lutgring and Limbago 2016; Guh et al. 2014). The epidemiology is different in other countries. For example, VIM is endemic in Greece, KPC is the most common carbapenemase in Israel, and IMP is endemic in Japan (Lutgring and Limbago 2016). In addition, the highest KPC-mediated resistance in the middle east area has been observed in Afghanistan, Saudi Arabia, and Jordan followed by NDM in Pakistan and OXA in Turkey and Pakistan (Zahedi Bialvaei et al. 2015). Therefore, antimicrobial resistance surveillance is essential for providing the necessary information for formulating local and international antimicrobial guidelines. Phenotypic methods defined by the Clinical and Laboratory Standards Institute (CLSI) to detect carbapenemase producers include the modified Hodge test (removed from the M100-S28 in 2018; CLSI), the Carba NP test, and most recently the modified carbapenem inactivation method ( $\mathrm{mCIM}$ ) (Cunningham et al. 2017; Pierce et al. 2017). While the Carba NP test is relatively easy to implement in the clinical laboratory, the $\mathrm{mCIM}$ has been found to be sensitive and specific in several recent studies and easy to perform and implement. Also, it utilizes low-cost materials that are readily available in clinical laboratories (Pierce et al. 2017; Tamma et al. 2017).

Although molecular methods remain the gold standard, they are costly, limited by the targets used specifically in the test, and not accessible to all microbiology laboratories throughout the world (Clarridge 3rd 2004). These methods can only detect known carbapenemaseencoding genes, and the number of carbapenemaseencoding genes and allelic variants thereof is expanding rapidly. In contrast, a phenotypic assay may detect carbapenemase activity irrespective of the carbapenemaseencoding gene sequence. In addition, timely detection of carbapenemases is essential for developing strategies to control the spread of infections by carbapenem-resistant isolates and related morbidity and mortality in particular regions. Therefore, the aims of this study were the characterization of carbapenemase activity in extensively drug-resistant (XDR) A. baumannii, K. pneumoniae, and E. coli clinical isolates and comparing the sensitivity and specificity of the modified Hodge test (MHT), Carba NP test, and $\mathrm{mCIM}$ in detecting carbapenem resistance.

\section{Methods}

\section{Bacterial isolates}

A total of 122 non-duplicate carbapenem-resistant clinical isolates were analyzed. The isolates included 77 K. pneumoniae, 39 A. baumannii, and six E. coli had been collected at various wards between May 2017 and February 2019 in 1000-bed tertiary care of Milad hospital, Tehran, Iran. Bacterial identification was performed by standard biochemical and microbiological tests. All isolates were stored at $-70{ }^{\circ} \mathrm{C}$ in trypticase soy broth with $15 \%$ glycerol and were subcultured twice on blood agar plates (Merck, Germany) prior to testing. The isolates were obtained from urine specimens (43, $35.2 \%)$, followed by tracheal aspirate/fluid (35, 28.7\%), wound and soft tissue specimens $(34,27.9 \%)$, blood (6, $4.9 \%)$, sputum $(3,2.5 \%)$, bronchoalveolar lavage (1, $0.8 \%)$. Patient's age ranged from 1 to 93 years old (61.4 $\pm 20.43), 73$ (59.8\%) were from female patients, while 49 (40.1\%) from males. As a control, 18 carbapenemresistant, KPC-2 type carbapenemase-producing $K$. pneumoniae clinical isolates were used in this study (Wang et al. 2011).

\section{Antimicrobial susceptibility testing}

The antimicrobial susceptibility of the isolated bacteria was determined in vitro, utilizing the disc diffusion method in accordance with the CLSI criteria (Clinical and Laboratory Standards Institute (CLSI) 2018). The tested antibiotics included ceftriaxone, cefotaxime, amoxicillin, cefepime, tazocin, ceftazidime, ciprofloxacin, gentamicin, and colistin (MAST Diagnostics, Merseyside, UK). Susceptibility testing for meropenem and/or imipenem was performed according to the CLSI reference by using $\mathrm{E}$ test method (Liofilchem, Italy). Carbapenem-resistant isolates were selected using the CLSI M100-S standard (27th edition) definition, i.e., not susceptible (intermediate or resistant, minimum inhibitory concentrations (MICs) of $\geq 2 \mu \mathrm{g} / \mathrm{ml}$ ) to 
meropenem and/or imipenem, as defined by the current (Miller et al. 2017).

\section{The modified Hodge test}

The MHT was carried out on all isolates to detect carbapenemase activity as described by CLSI (Clinical and Laboratory Standards Institute 2017). Briefly, an inoculum of E. coli ATCC 25922 was adjusted to 0.5 McFarland turbidity standard, and then a 1/10 dilution was inoculated on the surfaces of Mueller-Hinton agar plates (BD Ltd, USA) by swabbing. Next, after the plates were left undisturbed for $10 \mathrm{~min}$ at room temperature, a 10- $\mu$ g meropenem disk (Oxoid, UK) was placed in the center of each plate. Subsequently, suspected bacteria grown overnight on blood agar plate were inoculated onto the plate in a straight line from the edge of the disk to the periphery of the plate (without touching the disc) by swabbing. The plate was incubated overnight at $37^{\circ} \mathrm{C}$ in ambient air for 16-24 h. In negative isolates, the clear zones around the disk remain homogeneous, while carbapenemase-producing isolates cause cloverleaf-like indentation.

\section{Carba NP and CarbAcineto NP}

All isolates have also been tested for carbapenemase activity with Carba NP and CarbAcineto NP as defined by CLSI (Clinical and Laboratory Standards Institute 2017). Briefly, one third to one half of a $10-\mu$ l inoculation loop of the tested isolate, recovered from Mueller-Hinton Agar (BD Ltd, USA), was resuspended in $100 \mu \mathrm{l}$ of commercially available lysis buffer (B-PERII, Thermo Scientific Pierce, Rockford, USA). Next, $100 \mu$ l of diluted phenol red (Merck, Germany) solution containing 0.1 $\mathrm{mM} \mathrm{ZnSO}_{4}$ (Merck, Germany) $(\mathrm{pH}=7.8)$ and $6 \mathrm{mg} / \mathrm{ml}$ Imipenem was added. The phenol red solution, with no antibiotic was used as a control tube for each isolate. Both tubes were vortexed and incubated at $37{ }^{\circ} \mathrm{C}$ for a maximum of $2 \mathrm{~h}$. The color of the test tube changed to full yellow or orange, resulting from the hydrolysis of imipenem into a carboxylic derivative, leading to a decrease of the $\mathrm{pH}$ value (Dortet et al. 2014). For Acinetobacter, this protocol has two modifications: the use of a full 10- $\mu$ l loop of culture as an inoculum in order to increase the enzyme quantity and $100 \mu \mathrm{NaCl}(5 \mathrm{M})$ solution instead of the lysis buffer, avoiding any buffer effect.

\section{The modified carbapenem inactivation method}

The mCIM was performed as described earlier by van der Zwaluw et al. (2015), with some modifications. Briefly, a suspension was made with a $10-\mu \mathrm{L}$ inoculation loop from a 1-day-old culture, taken from a MuellerHinton agar plate in $500 \mu \mathrm{L}$ of sterile tryptic soy broth (TSB; Merck, Germany) and vortexed to obtain a homogenous suspension. Subsequently, a 10- $\mu$ g meropenem disk (Oxoid, UK) was immersed in the suspension and incubated for $2-3 \mathrm{~h}$ at $37{ }^{\circ} \mathrm{C}$. After incubation, the disk was carefully picked from the suspension using a forceps, placed on a Mueller-Hinton Agar plate preinoculated with a susceptible E. coli ATCC 25922 using a suspension equivalent to $0.5 \mathrm{McF}$ arland and subsequently incubated overnight at $37{ }^{\circ} \mathrm{C}$ in ambient air. A zone of $\leq 15 \mathrm{~mm}$ was considered positive for carbapenemase production, and a clear zone of $\geq 19 \mathrm{~mm}$ was considered negative. Zones of 16 to $18 \mathrm{~mm}$ or $\geq 19 \mathrm{~mm}$ with colonies present within the zone were considered indeterminate. Quality control was performed by testing a carbapenemase-positive (K. pneumoniae ATCC BAA$1705)$ and a carbapenemase-negative (K. pneumoniae ATCC BAA-1706) control strain on each day of testing. For additional controls, meropenem disks were incubated in Trypticase soy broth (TSB) or water alone (no organisms) for $2 \mathrm{~h}$ at $37^{\circ} \mathrm{C}$. The dry meropenem disk were also applied to the E. coli lawn, and zones were evaluated after overnight incubation to ensure they fell within CLSI quality control (QC) ranges for meropenem and E. coli ATCC 25922.

\section{Detection of carbapenem resistance genes}

Total DNA was extracted from all strains using the High Pure Template Kit (Roche Diagnostics, Germany) following the manufacturer's instructions. Five carbapenemase genes, including $b l a_{\mathrm{KPC}}, b l a_{\mathrm{NDM}}$, bla $a_{\mathrm{OXA}-48}$-like, $b l a_{\mathrm{IMP}}$, and $b l a_{\mathrm{VIM}}$ genes, were amplified using previously described primers (Schechner et al. 2009; Nordmann et al. 2011; Poirel et al. 2012; Pavelkovich et al. 2014). Amplification was performed in the thermal cycler (Eppendorf, Germany) and the amplified products were analyzed in 2\% $(\mathrm{w} / \mathrm{v})$ agarose gel $(100 \mathrm{~V}$ for $45 \mathrm{~min})$. Quality control included testing an isolate positive or negative for each target on each day of testing. Additionally, a 16S rRNA gene internal control was included in each PCR. Of note, multiplex polymerase chain reaction (PCR) was repeated for isolates that showed discrepant results in the form of negative PCR and positive Carba NP test or mCIM.

\section{Statistical analysis}

Data were analyzed with SPSS 23.0 (SPSS Inc., Chicago, IL). Diagnostic sensitivity and specificity calculations with $95 \%$ confidence intervals were done as described by Pasteran et al. (2009), using the results of carbapenem resistance gene PCR as the gold standard. Indeterminate or invalid results were classified as false-negative results when they occurred in carbapenemase-producing isolates and as false-positive results when they occurred in non-carbapenemase-producing isolates. The kappa coefficient was calculated to assess agreement between testing sites. Comparison between groups was performed by 
$\mathrm{X}^{2}$ and Fisher's exact test for qualitative variables. Statistical significance was set at $p<0.05$.

\section{Results}

\section{Antimicrobial susceptibility profile}

The results of the antimicrobial susceptibility testing indicated that majority of $K$. pneumoniae and A. baumannii isolates were resistant to ceftriaxone, cefotaxime, cefepime, tazocin, amoxicillin clavulanic acid, ceftazidime, and gentamicin, which indicates that these isolates were XDR. Also, almost all six E. coli isolates were completely resistant to the studied antibiotics except colistin. Antimicrobial susceptibility profiles of the isolates are shown in Table 1.

\section{Phenotypic detection of carbapenemase production}

To evaluate phenotypical tests for carbapenemase production, three methods the MHT, Carba NP test, and mCIM were used. All the positive controls were positive in all the three methods. There were no falsepositive results with all three methods. Discriminatory power of the methods in comparison to PCR was statistically significant $(p<0.0001)$. The positivity of the MHT and the Carba NP and mCIM tests according to the bacteria are shown in Table 2 .

\section{MHT test results}

All 122 isolates of carbapenem-resistant bacteria were tested, which $70(57.3 \%)$ isolates showed positive results by the MHT. There were observed that 24 isolates had false-negative results by the MHT, which were positive for carbapenemase genes in gold-standard PCR. The false-negative results missed by the MHT were linked to 13, 10, and one isolate of A. baumannii, K. pneumoniae, and $E$. coli, respectively. In addition, bla $a_{\mathrm{VIM}}(11 / 24)$, $b l a_{\mathrm{KPC}}(6 / 24), b l a_{\mathrm{IMP}}(4 / 24)$, and $b l a_{\mathrm{OXA}-48}(3 / 24)$ carbapenemases were among the most genes detected in this group. The sensitivity of the MHT was determined as $75.03 \%$ and a specificity of $100 \%$ in the isolates studied (Table 2).

\section{Carba NP test results}

Among the studied carbapenem-resistant bacteria, 84 $(68.8 \%)$ isolates were positive by Carba NP. The positivity of the Carba NP test is shown in Fig. 1. There were false-negative results in 16 isolates in Carba NP test. The false-negative results missed by the Carba NP test were linked to $b l a_{\mathrm{VIM}}(8 / 16), b l a_{\mathrm{IMP}}(5 / 16)$, and bla $_{\text {KPC }}(3 / 16)$ carbapenemases. The test was found negative in all those isolates displaying no reduced sensitivity against any of the carbapenems. The sensitivity of the Carba NP test was determined as $80.8 \%$ and a specificity of $100 \%$ in the isolates studied (Table 2).

\section{$\mathrm{mClM}$ test results}

All 122 isolates of carbapenem-resistant bacteria were tested, and among them 87 (71.3\%) isolates showed positive results by the mCIM (Fig. 1). It was observed that 12 isolates tested by the mCIM were determined as false negative. All the 12 isolates of positive carbapenemase gene, which were negative by the mCIM test, included 11 and one isolate of A. baumannii and K. pneumoniae, respectively. The false-negative results missed by the mCIM test were linked to $b l a_{\mathrm{VIM}}(6 / 12)$, bla $_{\mathrm{IMP}}(3 / 12)$, $b l a_{\mathrm{KPC}}(2 / 12)$, and $b l a_{\mathrm{OXA}-48}(1 / 12)$ carbapenemases.

All the isolates were detected to be positive by the end of $6 \mathrm{~h}$. The negative isolates were incubated overnight, but the result did not change. All the isolates displaying no reduced sensitivity against any of the carbapenems were found to be negative by the mCIM test. The sensitivity and specificity of the mCIM test in the isolates studied was determined to be $90.4 \%$ and $100 \%$, respectively. We observed that the mCIM test has a slightly higher sensitivity than the Carba NP test $(90.4 \%$ vs. $80.8 \%$, respectively; $p=0.018$ ).

\section{Detection of carbapenemase genes}

All isolates were tested for five carbapenemase genes by PCR. Of all carbapenem-resistant isolates, PCR results demonstrated that 119 (97.5\%) isolates harbored at least a carbapenemase gene; none of the five carbapenemase genes were detected in the isolates by the PCR method (Fig. 2). One isolate yielding carbapenemase production by the mCIM test was negative for the evaluated genes. The number of isolates that carried these genes is shown in Table 3. The most frequently identified carbapenemase genes were $b l a_{\mathrm{KPC}}$ identified in 59 isolates (48.3\%), bla $a_{\mathrm{VIM}}$ identified in 49 isolates (40.1\%), followed by

Table 1 Antimicrobial susceptibility testing for 122 nonduplicated isolates of Klebsiella pneumoniae, Acinetobacter baumannii, and Escherichia coli strains isolated over study period

\begin{tabular}{|c|c|c|c|c|c|c|c|c|c|c|c|c|c|c|c|c|c|c|c|c|c|c|}
\hline \multirow[t]{2}{*}{ Bacteria } & \multicolumn{2}{|c|}{ CIP } & \multicolumn{2}{|c|}{ GM } & \multicolumn{2}{|c|}{ CAZ } & \multicolumn{2}{|c|}{ CRO } & \multicolumn{2}{|c|}{ CTX } & \multicolumn{2}{|c|}{ AMS } & \multicolumn{2}{|c|}{ CPM } & \multicolumn{2}{|l|}{$\mathrm{TZ}$} & \multicolumn{2}{|c|}{ CS } & \multicolumn{2}{|c|}{ IPM } & \multicolumn{2}{|c|}{ MEM } \\
\hline & $\mathbf{R}$ & $S$ & $\mathbf{R}$ & $S$ & $\mathbf{R}$ & $S$ & $\mathbf{R}$ & $S$ & $\mathbf{R}$ & $S$ & $\mathbf{R}$ & $\bar{S}$ & $\mathbf{R}$ & 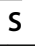 & $\mathbf{R}$ & $S$ & $\mathbf{R}$ & $S$ & $\mathbf{R}$ & $S$ & $\mathbf{R}$ & $\mathrm{s}$ \\
\hline K. pneumoniae $(n=77)$ & 76 & 1 & 76 & 1 & 76 & 1 & 76 & 0 & 76 & 1 & 77 & 0 & 76 & 0 & 76 & 1 & 16 & 61 & 75 & 2 & 75 & 2 \\
\hline A. baumannii $(n=39)$ & 39 & 0 & 39 & 0 & 39 & 0 & 39 & 0 & 39 & 0 & 39 & 0 & 39 & 0 & 39 & 0 & 1 & 38 & 39 & 0 & 39 & 0 \\
\hline E. coli $(n=6)$ & 6 & 0 & 5 & 1 & 5 & 1 & 6 & 0 & 6 & 0 & 6 & 0 & 6 & 0 & 6 & 0 & 0 & 6 & 6 & 0 & 6 & 0 \\
\hline
\end{tabular}

CRO ceftriaxone, CTX cefotaxime, AMS amoxicillin, CPM cefepime, TZ tazocin, CAZ ceftazidime, CIP ciprofloxacin, GM gentamicin, CS colistin, IPM imipenem, MEM meropenem 
Table 2 Performance of three phenotypic methods compared with the molecular detection of carbapenemase-producing isolates in the study

\begin{tabular}{|c|c|c|c|c|c|c|}
\hline \multirow[t]{2}{*}{ Bacteria } & \multirow{2}{*}{$\begin{array}{l}\mathrm{mCIM}^{\mathrm{a}}(\%) \\
(95 \% \mathrm{Cl}), n=122 \\
\text { Sensitivity }\end{array}$} & \multicolumn{2}{|c|}{$\begin{array}{l}\text { CarbaNP (\%) } \\
(95 \% \mathrm{Cl}), n=122\end{array}$} & \multicolumn{3}{|c|}{$\begin{array}{l}\mathrm{MHT}^{\mathrm{b}}(\%) \\
(95 \% \mathrm{Cl}), n=122\end{array}$} \\
\hline & & Specificity & Sensitivity & Specificity & Sensitivity & Specificity \\
\hline K. pneumoniae $(n=77)$ & 96.25 & 100 & 91.66 & 100 & 77 & 100 \\
\hline A. baumannii $(n=39)$ & 79.71 & 100 & 56.52 & 100 & 75 & 100 \\
\hline E. coli $(n=6)$ & 85.71 & 100 & 100 & 100 & 50 & 100 \\
\hline Total & 90.4 & 100 & 80.8 & 100 & 75.03 & 100 \\
\hline
\end{tabular}

${ }^{\mathrm{a}}$ Modified carbapenem inactivation method; ${ }^{\mathrm{b}}$ Modified Hodge test

bla $a_{\mathrm{IMP}}(31,25.4 \%)$ and $b l a_{\mathrm{OXA}-48}(9,7.3 \%)$, whereas $b l a_{\mathrm{NDM}}$ was not detected in this study. In addition, a high percentage $54(70.1 \%)$ of $K$. pneumoniae isolates carried $b l a_{\mathrm{KPC}}$, while only three and two isolates of $A$. baumannii and E. coli, respectively, contained these resistant genes. Co-production of 'KPC and VIM', 'KPC and IMP', and 'KPC and OXA-48' was detected in nine (K. pneumoniae), seven (five $K$. pneumoniae and two $E$. coli), and three (K. pneumoniae) isolates, respectively.

\section{Discussion}

Since the emergence of carbapenem resistance among GNB some years ago, they have become one of the major causes of death among hospital-acquired infections (Juhász et al. 2018). These organisms are also considered as public health threat worldwide (Tamma et al. 2016; Illés et al. 2019). This has raised attention towards seeking accurate and rapid methods for detection of carbapenemases via phenotypic or genotypic approaches, which are a chief cause of spread of carbapenem resistance (Bialvaei et al. 2016). In this study, we evaluated three different phenotypic methods for detection of carbapenemases in carbapenem-resistant K. pneumoniae, A. baumannii, and E. coli. In addition, a conventional PCR was performed to detect five carbapenemase-encoding genes as a reference method (Tijet et al. 2016; Zhou et al. 2018).

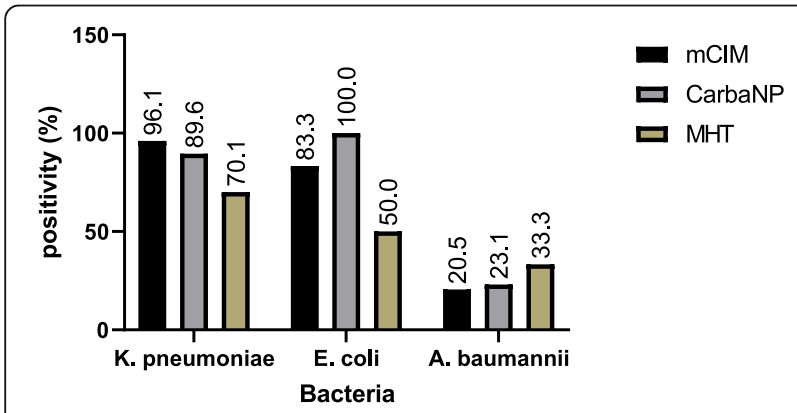

Fig. 1 The positivity of the different phenotypic test to detection of carbapenemase production by bacteria. mCIM modified carbapenem inactivation method, MHT modified Hodge test
The results of this study showed that the antibiotic resistance rates are high among studied clinical strains. In line with other studies conducted in Iran, almost all isolates were resistant to three or more antibiotics tested except colistin, indicating the highest antibacterial activity (Ranjbar and Farahani 2019). In the present study, high MIC values for carbapenems were detected and indicated a markedly reduced efficacy of these agents that could be due to their uncontrolled availability and/or overuse. In addition, we have shown recently that the prevalence of MDR A. baumannii in Iran increased from $50 \%$ in $2001-2007$ to $74 \%$ in 2010-2015, with a mean prevalence of $71 \%$ (Bialvaei et al. 2017). The trade among nations, for instance, Iran, Iraq, and Turkey, which reports the highest number of MDR cases is another possible reason behind such increase in the prevalence of resistance.

The PCR results, as the gold standard technique, confirmed that 119 isolates harbored one or more carbapenemase genes, $b l a_{\mathrm{KPC}}$ and $b l a_{\mathrm{VIM}}$ being the most common, in agreement with some studies reporting the high prevalence of $b l a_{\mathrm{KPC}}$ and bla $a_{\mathrm{VIM}}$ carbapenemases (Papadimitriou-Olivgeris et al. 2019). However, bla $a_{\mathrm{NDM}}$ was not detected in any of the investigated strains, while in a study by (Hosseinzadeh et al. 2018), more than $10 \%$ of the isolates carried the $b l a_{\mathrm{NDM}}$ gene. Co-production of different carbapenemases in a single isolate being reported increasingly for several Enterobacteriaceae species in various studies (Poirel et al. 2004; Bakthavatchalam et al. 2016; Cizmeci et al. 2017). In our collection, we have identified nine $K$. pneumoniae isolates co-producing ' $\mathrm{KPC}$ and VIM', five $K$. pneumoniae and two E. coli isolates coproducing 'KPC and IMP' and three K. pneumoniae isolate co-producing 'KPC and OXA-48' carbapenemases.

Recently, some phenotypic tests were designated for laboratory detection of carbapenemase activity. Although some studies have emphasized the $100 \%$ sensitivity and specificity, some other studies have not confirmed these findings in comparison with molecular methods (Hammoudi et al. 2014; Akhi et al. 2017). Therefore, proper performance of these methods is necessary under different conditions with various isolates obtained 


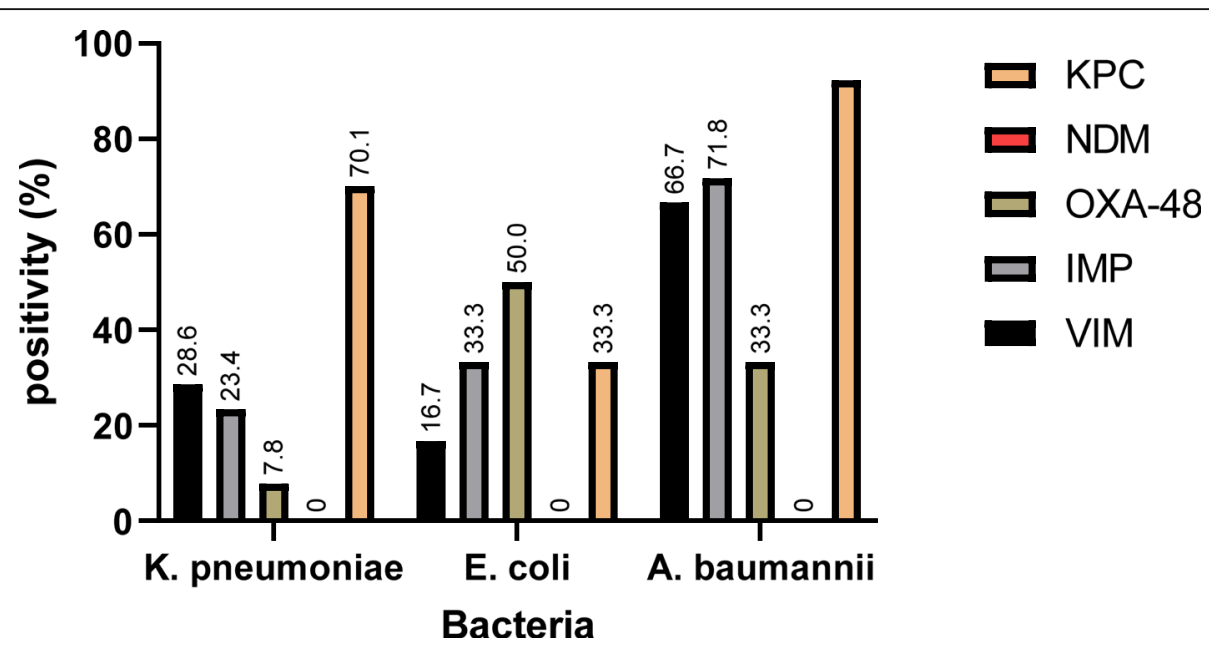

Fig. 2 PCR carbapenemase screening results of 122 carbapenem-resistant clinical isolates of Acinetobacter baumannii, Klebsiella pneumoniae, and Escherichia coli

worldwide. MHT was recommended by the Clinical and Laboratory Standards Institute, Performance standards for antimierobial susceptibility testing (2009) as a screening method for carbapenemase. However, it has been removed from the recent guideline (Clinical and Laboratory Standards Institute (CLSI) 2018). The advantages of the method include it being easy to perform and not needing special reagents or media (Akhi et al. 2017). The sensitivity and specificity of the MHT in our study was lower than in the results obtained by two other methods (Table 2). The Carba NP test was developed by Nordmann \& Poirel (Nordmann et al. 2012) in 2012; however, this method was subsequently modified. Carba NP, with high sensitivity and rapid detection $(\leq 2 \mathrm{~h})$, can detect not only all the known carbapenemases, but it identifies also newly emerging carbapenemases, compared with molecular methods (Nordmann et al. 2012). In this study, the Carba NP test had a sensitivity of $80.8 \%$ and a specificity of $100 \%$. This agrees with several studies evaluating the Carba NP test versus gold-standard PCR, which reported variable sensitivities of $72-93 \%$ and specificity of $100 \%$ (Tijet et al. 2013; Österblad et al. 2014; Hombach et al. 2015; Bayramoğlu et al. 2016a). Many studies have attributed the variable sensitivities and false-negative results encountered with the Carba NP test to many factors, including enzymes with weak carbapenemase activity (e.g., $b l a_{\mathrm{OXA}-48 \text {-like }}$ enzymes and $b l a_{\mathrm{GES}-5}$ ), isolates with mucoid property, size of the bacterial inoculum, early reading before completion of $2 \mathrm{~h}$ of incubation, and present but unexpressed carbapenemase genes (Österblad et al. 2014). In agreement with the current study, several studies reported false-negative Carba NP tests with the same dominating enzymes (NDM, KPC, and VIM) and related to mucoid Klebsiella strains, besides other factors linked to agar type and ion content for cultivation of the isolate (Hombach et al. 2015). In this study, the falsenegative results missed by the Carba NP test were linked to $b l a_{\mathrm{VIM}}, b l a_{\mathrm{IMP}}$, and $b l a_{\mathrm{KPC}}$ carbapenemases.

Recently, the CIM test was introduced and has been shown to be highly sensitive and specific for detection of any type of carbapenemase activity in GNB (van der Zwaluw et al. 2015). We believe that although the CIM test is not as rapid as the Carba NP test ( $8 \mathrm{~h}$ vs. $2 \mathrm{~h}$ ), it is a highly sensitive, simple, and cost-effective method that can be used in clinical laboratories, particularly those with limited resources, for early detection of carbapenemases. However, the mCIM utilizes readily available reagents not requiring reagent preparation, and results are more objective in nature, as a zone diameter reading is used for interpretation of results (Pierce et al. 2017). In this study, mCIM results gave a sensitivity of $90.4 \%$ and a specificity of $100 \%$. These results are in accordance with many other studies evaluating CIM, which showed low false-negative results with a sensitivity of 98.8\% (Bayramoğlu et al. 2016a; Bayramoğlu et al. 2016b; Tijet et al. 2016; Laolerd et al. 2018). Like our study, these studies reported no false-positive results, with a specificity of $100 \%$. Jing et al. (2018) introduced the Simplified carbapenem inactivation method (sCIM), which instead of incubating the antibiotic disk in the organism culture media for $4 \mathrm{~h}$ as in the mCIM, the organism to be tested was smeared directly onto an antibiotic disk in the sCIM. Based on their results, the sCIM showed high specificity and sensitivity comparable to PCR but has the advantage of being more userfriendly. Yamada et al. (2019) evaluated the detectability of MBL-producing Enterobacterales against three types of MBL inhibitors used in combination with a mCIM. Although inhibitor-combination mCIMs were highly specific $(99.0-100 \%)$ for the detection of MBL 
Table 3 The results of $\mathrm{MHT}^{\mathrm{a}}$, Carba NP, and $\mathrm{mCIM}^{\mathrm{b}}$ for isolates tested $(n=122)$

\begin{tabular}{|c|c|c|c|c|c|}
\hline \multirow[t]{2}{*}{ Species $(n)$} & \multirow{2}{*}{$\begin{array}{l}\text { Carbapenemase } \\
\text { gene }\end{array}$} & \multirow{2}{*}{$\begin{array}{l}\text { Meropenem } \\
\text { MIC }^{c}(\mu \mathrm{g} / \mathrm{ml})\end{array}$} & \multicolumn{3}{|c|}{ Test result for } \\
\hline & & & MHT & Carba NP & $\mathrm{mCIM}$ \\
\hline Klebsiella pneumoniae (1) & KPC & 0.094 & - & - & - \\
\hline K. pneumoniae (1) & $\mathrm{VIM}+\mathrm{KPC}$ & 1 & + & - & - \\
\hline K. pneumoniae (1) & KPC & 1.5 & + & + & + \\
\hline K. pneumoniae (1) & $\mathrm{KPC}+\mathrm{IMP}$ & 1.5 & + & - & - \\
\hline K. pneumoniae (1) & KPC & 2 & + & - & + \\
\hline K. pneumoniae (1) & KPC & 3 & + & + & + \\
\hline K. pneumoniae (1) & VIM & 3 & + & + & + \\
\hline K. pneumoniae (1) & KPC & 6 & + & + & + \\
\hline K. pneumoniae (1) & $\mathrm{VIM}+\mathrm{KPC}$ & 8 & + & + & + \\
\hline K. pneumoniae (2) & KPC & 8 & + & - & + \\
\hline K. pneumoniae (2) & IMP & 12 & + & + & + \\
\hline K. pneumoniae (1) & $\mathrm{VIM}+\mathrm{KPC}$ & 12 & + & - & + \\
\hline K. pneumoniae (1) & VIM + KPC + OXA-48 & 12 & + & + & + \\
\hline K. pneumoniae (1) & VIM + IMP & 12 & + & + & + \\
\hline K. pneumoniae (3) & KPC & 12 & + & + & + \\
\hline K. pneumoniae (2) & $\mathrm{KPC}$ & 16 & + & + & + \\
\hline K. pneumoniae (1) & KPC & 16 & - & - & + \\
\hline K. pneumoniae (3) & IMP & 16 & + & + & + \\
\hline K. pneumoniae (1) & VIM + IMP & 16 & - & + & + \\
\hline K. pneumoniae (1) & $\mathrm{KPC}$ & 24 & + & + & + \\
\hline K. pneumoniae (1) & $\mathrm{KPC}+\mathrm{VIM}$ & 24 & + & + & + \\
\hline K. pneumoniae (8) & $\mathrm{KPC}$ & $>32$ & - & + & + \\
\hline K. pneumoniae (14) & KPC & $>32$ & + & + & + \\
\hline K. pneumoniae (1) & $\mathrm{VIM}+\mathrm{KPC}$ & $>32$ & + & + & + \\
\hline K. pneumoniae (3) & $\mathrm{VIM}+\mathrm{KPC}$ & $>32$ & - & + & + \\
\hline K. pneumoniae (1) & - & $>32$ & + & + & + \\
\hline K. pneumoniae (9) & IMP & $>32$ & - & + & + \\
\hline K. pneumoniae (5) & VIM & $>32$ & + & + & + \\
\hline K. pneumoniae (2) & $\mathrm{IMP}+\mathrm{KPC}$ & $>32$ & + & + & + \\
\hline K. pneumoniae (1) & VIM + IMP & $>32$ & + & + & + \\
\hline K. pneumoniae (1) & $\mathrm{VIM}+\mathrm{KPC}+\mathrm{IMP}$ & $>32$ & + & + & + \\
\hline K. pneumoniae (1) & VIM + OXA-48 + IMP & $>32$ & + & + & + \\
\hline K. pneumoniae (2) & $K P C+O X A-48$ & $>32$ & + & + & + \\
\hline K. pneumoniae (1) & $V I M+O X A-48$ & $>32$ & + & + & + \\
\hline Acinetobacter baumannii (1) & $I M P+V I M$ & 16 & - & - & - \\
\hline A. baumannii (1) & VIM & 16 & - & - & - \\
\hline A. baumannii (2) & KPC & 16 & + & + & + \\
\hline A. baumannii (1) & IMP & 16 & - & - & - \\
\hline A. baumannii (12) & VIM & $>32$ & - & - & - \\
\hline A. baumannii (5) & IMP & $>32$ & - & - & - \\
\hline A. baumannii (4) & KPC & $>32$ & + & + & + \\
\hline A. baumannii (5) & VIM & $>32$ & + & - & - \\
\hline A. baumannii (2) & VIM & $>32$ & + & + & + \\
\hline
\end{tabular}


Table 3 The results of $\mathrm{MHT}^{\mathrm{a}}$, Carba NP, and $\mathrm{mCIM}^{\mathrm{b}}$ for isolates tested $(n=122)$ (Continued)

\begin{tabular}{|c|c|c|c|c|c|}
\hline \multirow[t]{2}{*}{ Species $(n)$} & \multirow{2}{*}{$\begin{array}{l}\text { Carbapenemase } \\
\text { gene }\end{array}$} & \multirow{2}{*}{$\begin{array}{l}\text { Meropenem } \\
M^{\prime} C^{C}(\mu \mathrm{g} / \mathrm{ml})\end{array}$} & \multicolumn{3}{|c|}{ Test result for } \\
\hline & & & MHT & Carba NP & $\mathrm{mCIM}$ \\
\hline A. baumannii (2) & IMP & $>32$ & + & - & - \\
\hline A. baumannii (1) & VIM & $>32$ & + & + & - \\
\hline A. baumannii (1) & - & $>32$ & - & - & - \\
\hline A. baumannii (2) & VIM + IMP & $>32$ & - & - & - \\
\hline Escherichia coli (1) & OXA-48 + KPC & 16 & + & + & + \\
\hline E. coli (1) & OXA-48 & 16 & + & + & + \\
\hline E. coli (1) & OXA-48 & $>32$ & - & + & - \\
\hline E. coli (1) & OXA-48 & $>32$ & - & + & + \\
\hline E. coli (1) & IMP & $>32$ & - & + & + \\
\hline E. coli (1) & VIM & $>32$ & + & + & + \\
\hline
\end{tabular}

${ }^{\mathrm{a}}$ Modified Hodge test; ${ }^{\mathrm{b}}$ Modified carbapenem inactivation method; ${ }^{\mathrm{c}}$ Minimum inhibitory concentration

producers, they found that sensitivity was dependent on the inhibitor's concentration.

\section{Conclusions}

High prevalence of extensively drug-resistant A. baumannii, K. pneumoniae, and $E$. coli with resistance to different classes of antimicrobial agents mediated by carbapenemases can be a main challenge for treatment with serious implications. We found both the mCIM and the CLSI Carba NP test to be accurate for detection of carbapenemases among carbapenem-resistant isolates. However, the mCIM was superior in being of higher sensitivity compared with the Carba NP test. Overall, the mCIM and Carba NP test offer the chance for easy implementation of carbapenemase detection in routine laboratories and can be employed to give timely and actionable clinical results. Moreover, they can contribute to better antimicrobial stewardship of carbapenems through prudent control of carbapenemase producers.

\section{Code availability}

The code is available from the corresponding author upon request.

\section{Authors' contributions}

Abed Zahedi bialvaei participated in the methodology, data collection, data analysis and drafted a manuscript. Alireza Dolatyar Dehkharghani and Farhad Asgari participated in design of the study and critical revision of the manuscript for important intellectual content. Firouzeh Shamloo improved the writing of the manuscript. Parisa Eslami participated in the experiments. Mohammad Rahbar participated in study supervision and designed the experimental scheme, and carried out the overall planning and improvement of the manuscript. All authors have read and approved the final manuscript.

\section{Funding}

Research reported in this publication was supported by Elite Researcher Grant Committee under award number 943827 from the National Institute for Medical Research Development (NIMAD), Tehran, Iran.
Availability of data and materials

All data generated or analyzed during this study are included in this published article (and its tables and figures).

\section{Declarations}

Ethics approval and consent to participate

Not applicable

\section{Consent for publication}

The participant has consented to the submission of this article to the journal. We confirm that the manuscript, or part of it, has neither been published nor is currently under consideration for publication. This work and the manuscript were approved by all coauthors.

\section{Competing interests}

The authors declare that they have no conflicts of interest.

\section{Author details}

${ }^{1}$ Microbial Biotechnology Research Center, Iran University of Medical Sciences, Tehran, Iran. ${ }^{2}$ Department of Microbiology, Iranian Reference Health Laboratory Research Center, Ministry of Health and Medical Education,

Tehran, Iran. ${ }^{3}$ Department of Microbiology, Milad Hospital, Tehran, Iran.

Received: 23 March 2021 Accepted: 18 May 2021

Published online: 21 June 2021

\section{References}

Akhi MT, Khalili Y, Ghotaslou R, Kafil HS, Yousefi S, Nagili B, Goli HR (2017) Carbapenem inactivation: a very affordable and highly specific method for phenotypic detection of carbapenemase-producing Pseudomonas aeruginosa isolates compared with other methods. J Chemother 29(3):144149. https://doi.org/10.1080/1120009X.2016.1199506

Bakthavatchalam YD, Anandan S, Veeraraghavan B (2016) Laboratory detection and clinical implication of oxacillinase-48 like carbapenemase: the hidden threat. J Global Infect Dis 8:41

Bayramoğlu G, Ulucam G, Gençoğlu ÇÖ, Kılıç A, Aydın F (2016a) Comparison of the modified Hodge test and the Carba NP test for detection of carbapenemases in Enterobacteriaceae isolates. Mikrobiyoloji bulteni 50(1):110. https://doi.org/10.5578/mb.10861

Bayramoğlu G, Ulucam G, Gençoğlu Öç, Kılıç AO, Aydın F (2016b) Comparison of the modified Hodge test and the Carba NP test for detection of carbapenemases in Enterobacteriaceae isolates. Mikrobiyoloji bulteni 50(1):110. https://doi.org/10.5578/mb.10861

Bialvaei AZ, Kafil HS, Asgharzadeh M, Yousef Memar M, Yousefi M (2016) Current methods for the identification of carbapenemases. J Chemother 28(1):1-19. https://doi.org/10.1179/1973947815Y.0000000063 
Bialvaei AZ, Kouhsari E, Salehi-Abargouei A, Amirmozafari N, Ramazanzadeh R, Ghadimi-Daresajini A, Sedighi M (2017) Epidemiology of multidrug-resistant Acinetobacter baumannii strains in Iran: a systematic review and metaanalysis. J Chemother 29(6):327-337. https://doi.org/10.1080/1120009X.201 7.1338377

Cizmeci Z, Aktas E, Otlu B, Acikgoz O, Ordekci S (2017) Molecular characterization of carbapenem-resistant Enterobacteriaceae yields increasing rates of NDM-1 carbapenemases and colistin resistance in an OXA-48-endemic area. J Chemother 29(6):344-350. https://doi.org/10.1080/1120009X.2017.1323149

Clarridge JE 3rd (2004) Impact of 165 rRNA gene sequence analysis for identification of bacteria on clinical microbiology and infectious diseases. Clin Microbiol Rev 17(4):840-862. https://doi.org/10.1128/CMR.17.4.840862.2004

Clinical and Laboratory Standards Institute (2017) Performance standards for antimicrobial susceptibility testing; twenty-seventh informational supplement M100-S27. Clinical and Laboratory Standards Institute, Wayne

Clinical and Laboratory Standards Institute (CLSI) (2018) Performance standards for antimicrobial susceptibility testing, twenty-eighth information supplement

Clinical and Laboratory Standards Institute, Performance standards for antimierobial susceptibility testing (2009) Nineteenth information supplement. CLSI document M100-S19[S]. CLSI, Wayne

Cunningham SA, Limbago B, Traczewski M, Anderson K, Hackel M, Hindler J, Sahm D, Alyanak E, Lawsin A, Gulvik CA, de Man TJB, Mandrekar JN, Schuetz AN, Jenkins S, Humphries R, Palavecino E, Vasoo S, Patel R (2017) Multicenter performance assessment of Carba NP test. J Clin Microbiol 55(6):1954-1960. https://doi.org/10.1128/JCM.00244-17

Dortet L, Poirel L, Errera C, Nordmann P (2014) CarbAcineto NP test for rapid detection of carbapenemase-producing Acinetobacter spp. J Clin Microbiol 52(7):2359-2364. https://doi.org/10.1128/JCM.00594-14

Gniadek TJ, Carroll KC, Simner PJ (2016) Carbapenem-resistant non-glucosefermenting gram-negative bacilli: the missing piece to the puzzle. J Clin Microbiol 54(7):1700-1710. https://doi.org/10.1128/JCM.03264-15

Guh AY, Limbago BM, Kallen AJ (2014) Epidemiology and prevention of carbapenem-resistant Enterobacteriaceae in the United States. Expert Rev Anti-Infect Ther 12(5):565-580. https://doi.org/10.1586/14787210.2014.902306

Hammoudi D, Moubareck CA, Sarkis DK (2014) How to detect carbapenemase producers? A literature review of phenotypic and molecular methods. J Microbiol Methods 107:106-118. https://doi.org/10.1016/j.mimet.2014.09.009

Hombach M, von Gunten B, Castelberg C, Bloemberg GV (2015) Evaluation of the Rapidec Carba NP test for detection of carbapenemases in Enterobacteriaceae. J Clin Microbiol 53(12):3828-3833. https://doi.org/10.112 8/JCM.02327-15

Hosseinzadeh Z, Ebrahim-Saraie HS, Sarvari J, Mardaneh J, Dehghani B, RokniHosseini SMH, Motamedifar M (2018) Emerge of Bla NDM-1 and Bla OXA-48like harboring carbapenem-resistant Klebsiella pneumoniae isolates from hospitalized patients in southwestern Iran. J Chin Med Assoc 81(6):536-540. https://doi.org/10.1016/j.jcma.2017.08.015

Illés D, Urbán E, Lázár A, Nagy K, Ivány E, Kui B, Lemes K, Tajti M, Czakó L (2019) Az antibiotikumrezisztencia változása cholangitisben. Klinikai tapasztalataink= changes in antibiotic resistance in cholangitis. Our clinical experience. Orv Hetil 160(36):1437-1442. https://doi.org/10.1556/ 650.2019 .31456

Jing X, Zhou H, Min X, Zhang X, Yang Q, Du S, et al (2018) The simplified carbapenem inactivation method (sCIM) for simple and accurate detection of carbapenemase-producing gram-negative bacilli. Front Microbiol 9:2391.

Juhász E, Iván M, Pongrácz J, Kristóf K (2018) Uncommon non-fermenting gramnegative rods as pathogens of lower respiratory tract infection. Orv Hetil 159(1):23-30. https://doi.org/10.1556/650.2018.30926

Laolerd W, Akeda Y, Preeyanon L, Ratthawongjirakul P, Santanirand P (2018) Carbapenemase-producing carbapenem-resistant Enterobacteriaceae from Bangkok, Thailand, and their detection by the Carba NP and modified carbapenem inactivation method tests. Microb Drug Resist 24(7):1006-1011. https://doi.org/10.1089/mdr.2018.0080

Lutgring JD, Limbago BM (2016) The problem of carbapenemase-producingcarbapenem-resistant-Enterobacteriaceae detection. J Clin Microbiol 54(3): 529-534. https://doi.org/10.1128/JCM.02771-15

Miller SA, Hindler JA, Chengcuenca A, Humphries RM (2017) Use of ancillary carbapenemase tests to improve specificity of phenotypic definitions for carbapenemase-producing <span class="named-content genus-species" id= "named-content-1">Enterobacteriaceae</span>. J Clin Microbiol 55(6):18271836. https://doi.org/10.1128/JCM.00157-17
Nordmann P, Poirel L, Carrër A, Toleman MA, Walsh TR (2011) How to detect NDM-1 producers. J Clin Microbiol 49(2):718-721. https://doi.org/10.1128/ JCM.01773-10

Nordmann P, Poirel L, Dortet L (2012) Rapid detection of carbapenemaseproducing Enterobacteriaceae. Emerg Infect Dis 18(9):1503-1507. https://doi. org/10.3201/eid1809.120355

Österblad M, Hakanen AJ, Jalava J (2014) Evaluation of the Carba NP test for carbapenemase detection. Antimicrob Agents Chemother 58(12):7553-7556. https://doi.org/10.1128/AAC.02761-13

Papadimitriou-Olivgeris M, Bartzavali C, Lambropoulou A, Solomou A, Tsiata E, Anastassiou ED, Fligou F, Marangos M, Spiliopoulou I, Christofidou M (2019) Reversal of carbapenemase-producing Klebsiella pneumoniae epidemiology from blaKPC- to blaVIM-harbouring isolates in a Greek ICU after introduction of ceftazidime/avibactam. J Antimicrob Chemother 74(7):2051-2054. https:// doi.org/10.1093/jac/dkz125

Pasteran F, Mendez T, Guerriero L, Rapoport M, Corso A (2009) Sensitive screening tests for suspected class a carbapenemase production in species of Enterobacteriaceae. J Clin Microbiol 47(6):1631-1639. https://doi.org/1 0.1128/JCM.00130-09

Pavelkovich A, Balode A, Edquist P, Egorova S, Ivanova M et al (2014) Detection of carbapenemase-producing enterobacteriaceae in the Baltic countries and St. Petersburg area. Biomed Res Int 2014:548960-548960

Pierce VM, Simner PJ, Lonsway DR, Roe-Carpenter DE, Johnson JK, Brasso WB, Bobenchik AM, Lockett ZC, Charnot-Katsikas A, Ferraro MJ, Thomson RB Jr, Jenkins SG, Limbago BM, Das S (2017) Modified carbapenem inactivation method for phenotypic detection of carbapenemase production among Enterobacteriaceae. J Clin Microbiol 55(8):2321-2333. https://doi.org/10.1128/ JCM.00193-17

Poirel L, Héritier C, Tolün V, Nordmann P (2004) Emergence of oxacillinasemediated resistance to imipenem in Klebsiella pneumoniae. Antimicrob Agents Chemother 48(1):15-22. https://doi.org/10.1128/AAC.48.1.15-22.2004

Poirel L, Potron A, Nordmann P (2012) OXA-48-like carbapenemases: the phantom menace. J Antimicrob Chemother 67(7):1597-1606. https://doi. org/10.1093/jac/dks121

Ranjbar R, Farahani A (2019) Study of genetic diversity, biofilm formation, and detection of carbapenemase, MBL, ESBL, and tetracycline resistance genes in multidrug-resistant Acinetobacter baumannii isolated from burn wound infections in Iran. Antimicrob Resist Infect Control 8:1-11

Schechner V, Straus-Robinson K, Schwartz D, Pfeffer I, Tarabeia J, Moskovich R, Chmelnitsky I, Schwaber MJ, Carmeli Y, Navon-Venezia S (2009) Evaluation of PCR-based testing for surveillance of KPC-producing carbapenem-resistant members of the Enterobacteriaceae family. J Clin Microbiol 47(10):3261-3265. https://doi.org/10.1128/JCM.02368-08

Tamma PD, Goodman KE, Harris AD, Tekle T, Roberts A et al (2016) Comparing the outcomes of patients with carbapenemase-producing and noncarbapenemase-producing carbapenem-resistant Enterobacteriaceae bacteremia. Clin Infect Dis 64:257-264

Tamma PD, Opene BN, Gluck A, Chambers KK, Carroll KC et al (2017) Comparison of 11 phenotypic assays for accurate detection of carbapenemase-producing Enterobacteriaceae. J Clin Microbiol 55(4):1046-1055. https://doi.org/10.1128/ JCM.02338-16

Tijet N, Boyd D, Patel SN, Mulvey MR, Melano RG (2013) Evaluation of the Carba NP test for rapid detection of carbapenemase-producing Enterobacteriaceae and Pseudomonas aeruginosa. Antimicrob Agents Chemother 57(9):45784580. https://doi.org/10.1128/AAC.00878-13

Tijet N, Patel SN, Melano RG (2016) Detection of carbapenemase activity in Enterobacteriaceae: comparison of the carbapenem inactivation method versus the Carba NP test. J Antimicrob Chemother 71(1):274-276. https://doi. org/10.1093/jac/dkv283

van der Zwaluw K, de Haan A, Pluister GN, Bootsma HJ, de Neeling AJ, Schouls LM (2015) The carbapenem inactivation method (CIM), a simple and low-cost alternative for the Carba NP test to assess phenotypic carbapenemase activity in gram-negative rods. PLoS One 10(3):e0123690. https://doi.org/1 0.1371/journal.pone.0123690

Vardakas KZ, Tansarli GS, Rafailidis PI, Falagas ME (2012) Carbapenems versus alternative antibiotics for the treatment of bacteraemia due to Enterobacteriaceae producing extended-spectrum $\beta$-lactamases: a systematic review and meta-analysis. J Antimicrob Chemother 67(12):2793-2803. https:// doi.org/10.1093/jac/dks301

Wang P, Chen S, Guo Y, Xiong Z, Hu F, Zhu D, Zhang Y (2011) Occurrence of false positive results for the detection of carbapenemases in carbapenemase- 
negative Escherichia coli and Klebsiella pneumoniae isolates. PLoS One 6(10): e26356. https://doi.org/10.1371/journal.pone.0026356

Yamada K, Sasaki M, Imai W, Murakami H, Morita T, Aoki K, Ishii Y, Tateda K (2019) Evaluation of inhibitor-combination MCIM for detecting MBL-producing Enterobacterales using three MBL inhibitors. J Med Microbiol 68(11):16041606. https://doi.org/10.1099/jmm.0.001073

Zahedi Bialvaei A, Samadi Kafil H, Ebrahimzadeh Leylabadlo H, Asgharzadeh M, Aghazadeh M (2015) Dissemination of carbapenemases producing gram negative bacteria in the Middle East. Iranian J Microbiol 7:226

Zhou M, Wang D, Kudinha T, Yang Q, Yu S, Xu YC (2018) Comparative evaluation of four phenotypic methods for detection of class a and B carbapenemaseproducing Enterobacteriaceae in China. J Clin Microbiol 56(8). https://doi. org/10.1128/JCM.00395-18

\section{Publisher's Note}

Springer Nature remains neutral with regard to jurisdictional claims in published maps and institutional affiliations.

Ready to submit your research? Choose BMC and benefit from:

- fast, convenient online submission

- thorough peer review by experienced researchers in your field

- rapid publication on acceptance

- support for research data, including large and complex data types

- gold Open Access which fosters wider collaboration and increased citations

- maximum visibility for your research: over $100 \mathrm{M}$ website views per year

At BMC, research is always in progress.

Learn more biomedcentral.com/submissions 